MATEC Web of Conferences 46, 05008 (2016)

DOI: $10.1051 /$ matecconf $/ 20164605008$

(C) Owned by the authors, published by EDP Sciences, 2016

\title{
Reaction to fire of ETICS applied on wood particle board
}

\author{
Antonio Bonati and Vittorio Galimberti \\ Istituto per le Tecnologie della Costruzione - Italian National Council of Research San Giuliano \\ Milanese (Milan), Italy
}

\begin{abstract}
As well known the ETICS are diffusely used both for energy saving and thermal insulation reasons. They have been applied recently in wood buildings and in regions of southern Europe too due to green building and sustainability reasons.

ITC-CNR has tested a lot of building materials and developed good knowledge about reaction to fire since the 1980 and currently, ETICS fixed directly to particle wood panels have been investigated with several SBI tests.

In the case study are presented the main factors that can influence the fire reaction results when applied on wood structure are highlighted: the thickness of the insulating material, the presence of accidental damage, the flame attack from the inside.

From the results obtained by tests on samples prepared with simulated accidental damages and fire from inside, some considerations are made about the hazard due to this specific construction technology and others on limits of the type of actually used standards product classification.
\end{abstract}

\section{MATERIALS AND SYSTEMS USED IN THE STUDY}

The study was carried out at ITC Fire Laboratories in the 2015 on some ETICS of current production, usually sold on the market in kits, to be applied on masonry or wood based supports. For samples assembling were used the following components:

- Adhesive layer $(5 \mathrm{~mm})$ and base coat $(4 \mathrm{~mm})$ cement-based with calcium carbonate fillers, density $1750 \mathrm{~kg} / \mathrm{m}^{3}$.

- EPS insulating panels, pentane expanded, Fire Reaction Class E in accordance with EN 13501$1: 2007+\mathrm{A} 1: 2009[1]$, density $18 \mathrm{~kg} / \mathrm{m}^{3}$.

- Reinforcement by glass fibber net with mesh 4,15 ×3,80 mm, mass per unit area $155 \mathrm{~g} / \mathrm{m}^{2}$.

- Key coat and red finishing coat made of synthetic resin binder with $2 \mathrm{~mm}$ fillers added.

- Plastic anchors.

\section{PERFOMED TESTS}

The fire behaviour analysis of the different samples for comparison has been based on results from tests that have been done in accordance with EN 13823:2010+A1:2014 [2].

This is an Open Access article distributed under the terms of the Creative Commons Attribution License 2.0, which permits unrestricted use, distribution, and reproduction in any medium, provided the original work is properly cited. 


\section{MATEC Web of Conferences}

Table 1. Samples used in the SBI tests.

\begin{tabular}{|c|l|}
\hline SAMPLE & DESCRIPTION \\
\hline A & ETICS sample with thick EPS $200 \mathrm{~mm}$ applied on calcium silicate boards \\
\hline B & ETICS sample with thick EPS $200 \mathrm{~mm}$ applied on wood particle boards \\
\hline $\mathbf{C}$ & ETICS sample with thick EPS $40 \mathrm{~mm}$ applied on wood particle boards \\
\hline D & Sample with wood particle boards only \\
\hline $\mathbf{E}$ & $\begin{array}{l}\text { ETICS with thick EPS } 40 \mathrm{~mm} \text { applied on wood particle boards, } \\
\text { with artificial damage }(\text { little shallow cavity in the long wing surface } \\
\text { of rendering placed at } 15 \mathrm{~cm} \text { from the corner and } 15 \text { high } \\
\text { from the burner) } 20 \times 50 \times 15 \mathrm{~mm}\end{array}$ \\
\hline $\mathbf{F}$ & $\begin{array}{l}\text { ETICS sample with thick EPS } 40 \mathrm{~mm} \\
\text { applied behind on wood particle boards: sample reverse } \\
\text { assembled (flame against particle board) }\end{array}$ \\
\hline $\mathbf{G}$ & $\begin{array}{l}\text { ETICS sample with thick EPS } 200 \mathrm{~mm} \\
\text { applied behind on wood particle boards: sample reverse } \\
\text { assembled (flame against particle board) }\end{array}$ \\
\hline
\end{tabular}
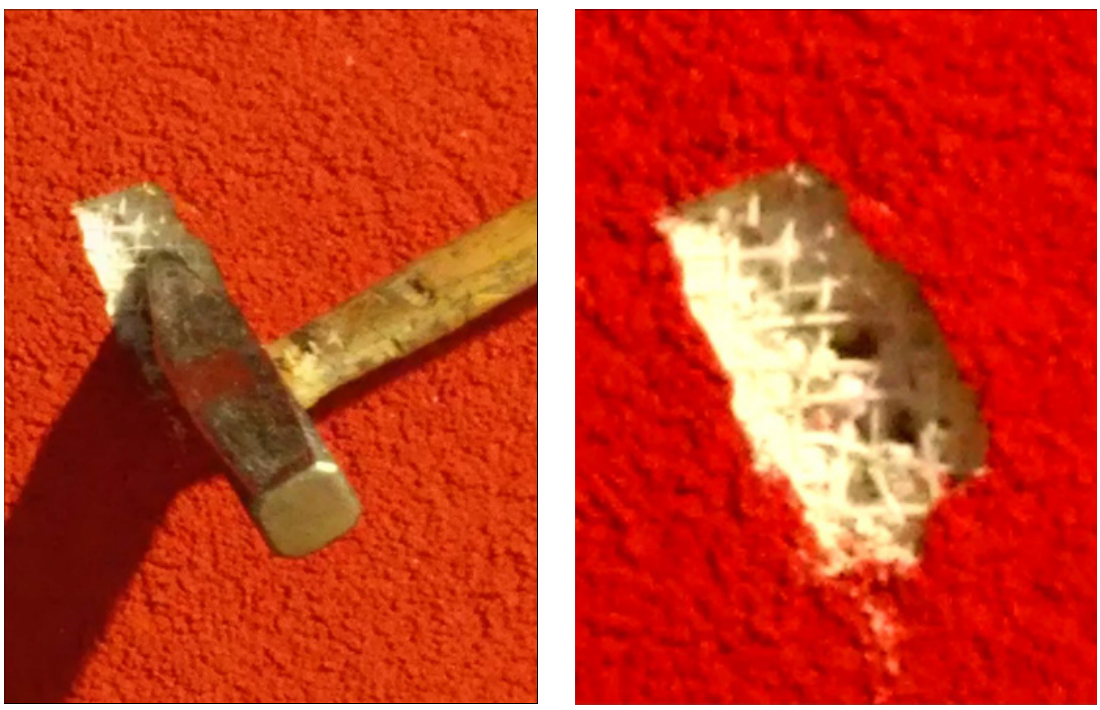

Figure 1. Damage manually done by hammer on Sample E.

The substrates that have been used in accordance with EN 13238:2010 [3] were the following:

- Calcium silicate boards, thickness $12 \mathrm{~mm}$, density $875 \mathrm{~kg} / \mathrm{m}^{3}$.

- Particle wood boards, thickness $12 \mathrm{~mm}$, density $650 \mathrm{~kg} / \mathrm{m}^{3}$.

All the samples have been assembled in accordance with annex D, ETAG 004 [4] in the laboratory and have been left there for a curing period of 28 days. Then samples have been placed for 8 weeks more in a conditioning room $\left(23 \pm 2{ }^{\circ} \mathrm{C} ; 50 \pm 5 \% \mathrm{RH}\right)$.

On the basis of the experimental data coming from the SBI tests done, some significant parameters have been compared. The data reported in this paper are not the result of an average data processing but the results of the tests that have been done on specific samples as listed in Table 1, samples selected, from a large number of sample tested, as to be representative of the fire behaviour of one samples typology. 
$2^{\text {nd }}$ International Seminar for Fire Safety of Facades, Lund (Sweden), 2016
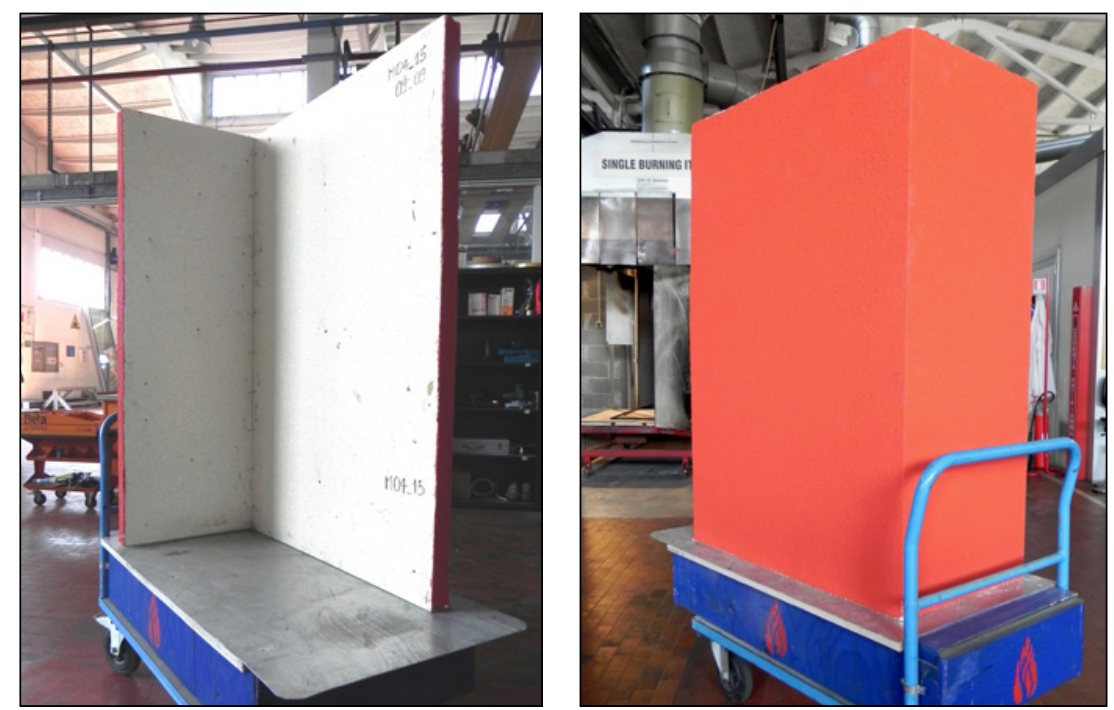

Figure 2. Inside and outside view of sample F reverse assembled.

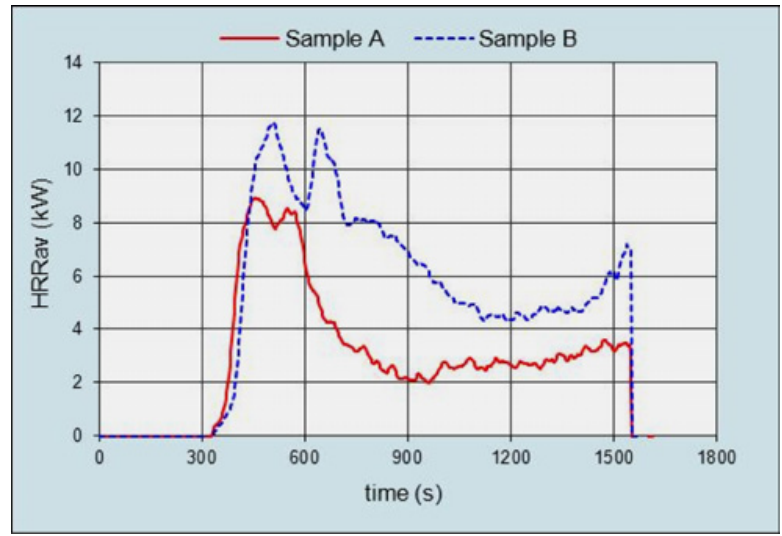

Figure 3. $\mathrm{HRR}_{\mathrm{av}}$ of samples $\mathrm{A}$ and $\mathrm{B}$.

Table 2. Main data from SBI tests of samples A and B.

\begin{tabular}{|c|cc|c|c|}
\hline Sample & Peak HRRav $(\mathrm{kW})$ & $\mathrm{t}-\mathrm{t}_{0}(\mathrm{~s})$ & THR $_{\mathrm{ta}}(\mathrm{MJ})$ & Figra $(\mathrm{W} / \mathrm{s})$ \\
\hline A & 8.9 & 153 & 2.8 & 64.60 \\
\hline B & 11.8 & 207 & 4.5 & 65.67 \\
\hline
\end{tabular}

\section{RESULTS: SUBSTRATE IN COMPARISON}

The following results have been processed from tests of samples " $\mathrm{A}$ " and "B" and aimed to point out the different fire behaviour of the same ETICS when assembled on calcium silicate boards (incombustible material) or on wood particle boards (fire reaction class D-s1, d0). 


\section{MATEC Web of Conferences}

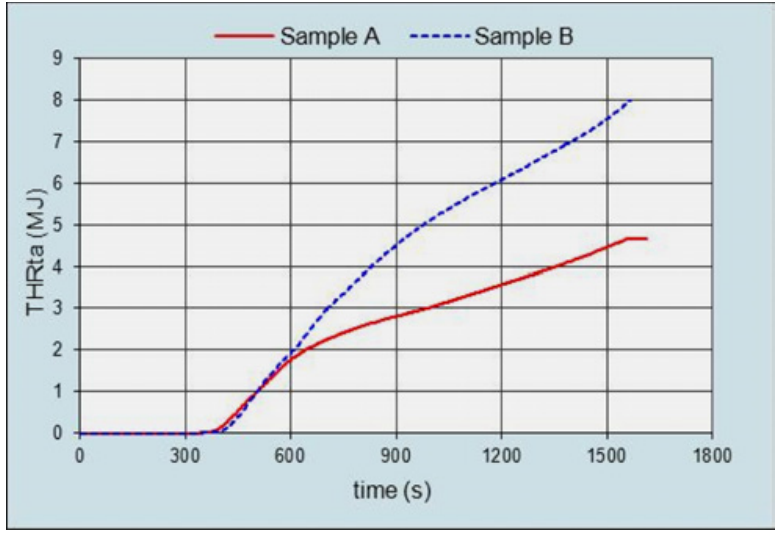

Figure 4. THR of samples A and B.



Figure 5. $\mathrm{SPR}_{\mathrm{av}}$ of samples $\mathrm{A}$ and $\mathrm{B}$.

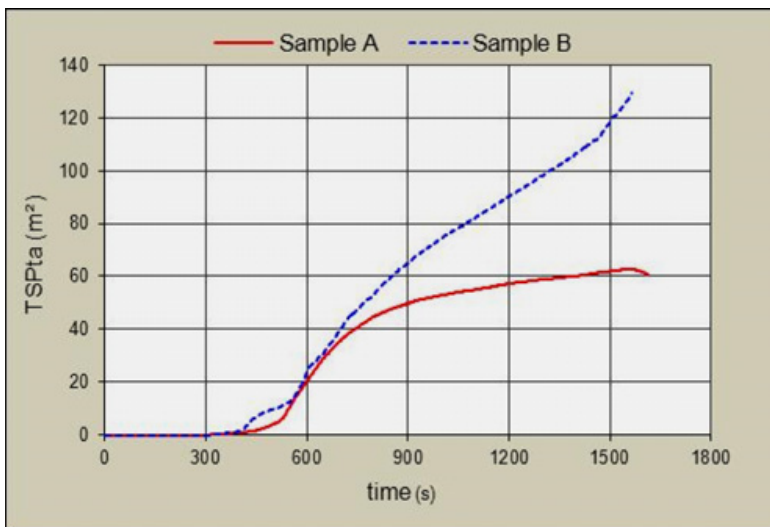

Figure 6. TSP of samples A and B. 
$2^{\text {nd }}$ International Seminar for Fire Safety of Facades, Lund (Sweden), 2016
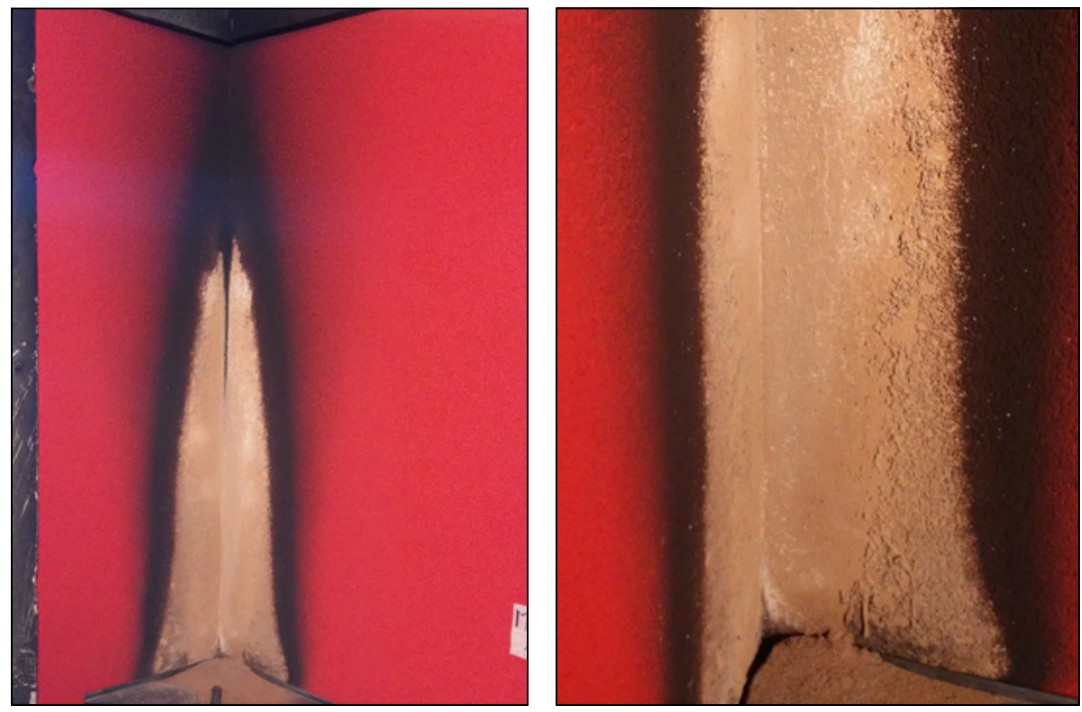

Figure 7. Sample A: typical burned surface after the test where no holes occurred. Damage from burning, soot deposition and discoloration.

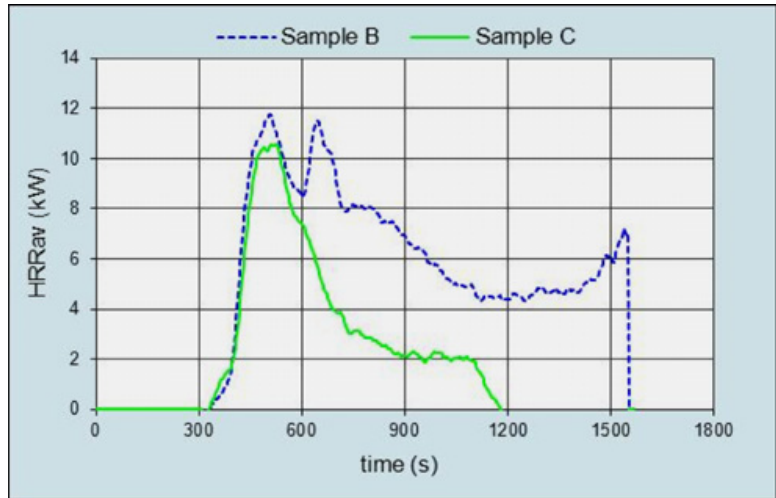

Figure 8. $\mathrm{HRR}_{\mathrm{av}}$ of samples $\mathrm{B}$ and $\mathrm{C}$.

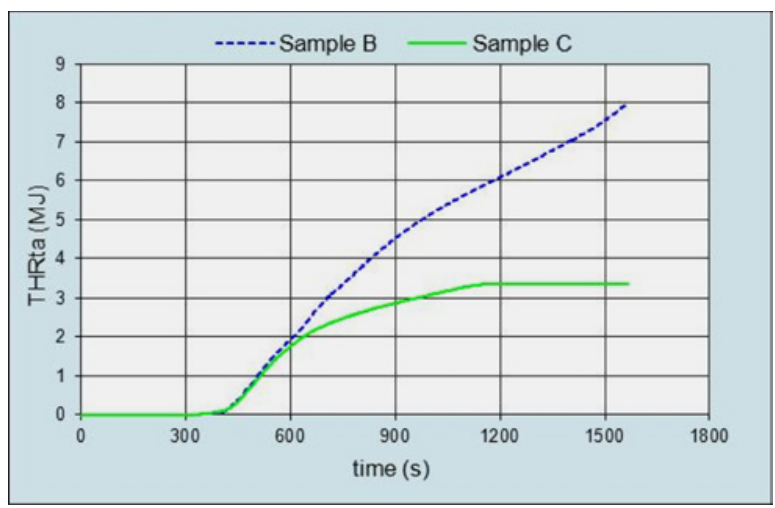

Figure 9. THR of samples B and C. 


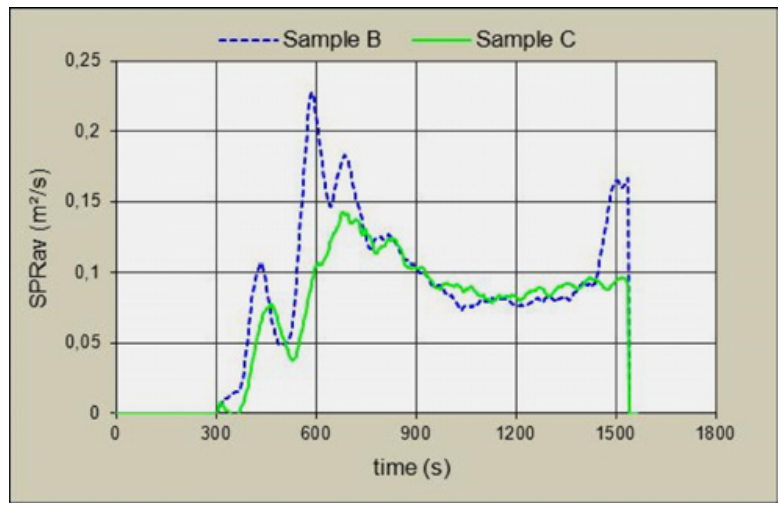

Figure 10. $\mathrm{SPR}_{\mathrm{av}}$ of samples $\mathrm{B}$ and $\mathrm{C}$.

Table 3. Main data from SBI tests of samples B and C.

\begin{tabular}{|c|cc|c|c|}
\hline Sample & Peak HRRav $(\mathrm{kW})$ & $\mathrm{t}-\mathrm{t}_{0}(\mathrm{~s})$ & $\mathrm{THR}_{\mathrm{ta}}(\mathrm{MJ})$ & Figra $(\mathrm{W} / \mathrm{s})$ \\
\hline $\mathrm{B}$ & 11.8 & 207 & 4.5 & 65.67 \\
\hline $\mathrm{C}$ & 10.6 & 225 & 2.9 & 58.92 \\
\hline
\end{tabular}

\subsection{Considerations}

$\mathrm{HRR}_{\mathrm{av}}$ samples trend is quite similar: initial peak is a not of a high level, due to organic component of the rendering layer, followed with strong decreasing.

The maintenance of a certain value of HRR which tends to increase slightly on continued testing it is due to an increase in surface temperature (modest flame spread on the surface) that makes liquefy modestly but continues the insulating material: melting, then decomposition followed by evaporation of low molecular weigh product [5].

The rendering layer, when, as in this case, does not tears and maintains its consistency (falls apart only in the cooling phase, at test end, under the action of the jet of water required to extinguish the burning sample) and protect the insulation material from the direct attack of flame (only burning at the foot of the melting party, the area just wide of the burner). This behaviour does not allow to call into question the type of substrate as trends resulting are very similar.

Same considerations can be made about the production of smoke.

\section{RESULTS: INSULATION LAYER THICKNESS IN COMPARISON}

The following results have been processed from tests of samples " $\mathrm{B}$ " and " $\mathrm{C}$ " and aimed to point out the different fire behaviour of the same ETICS but with different thickness (40 and $200 \mathrm{~mm}$ ) of the insulation layer when assembled on wood particle boards (fire reaction class D-s1, d0).

\subsection{Considerations}

As has been observed in the tests being compared before (Test A and B with different substrates) the integrity of the rendering layer ensures a similar behavior, even in the case of different thickness of insulation (otherwise it might happen at the same thickness but with different density [6]). Only little difference is seen in the maintenance phase of the HRR, following the initial peak, due to the different amount of insulating material which liquefies at the foot of the sample and participates in the combustion 
$2^{\text {nd }}$ International Seminar for Fire Safety of Facades, Lund (Sweden), 2016

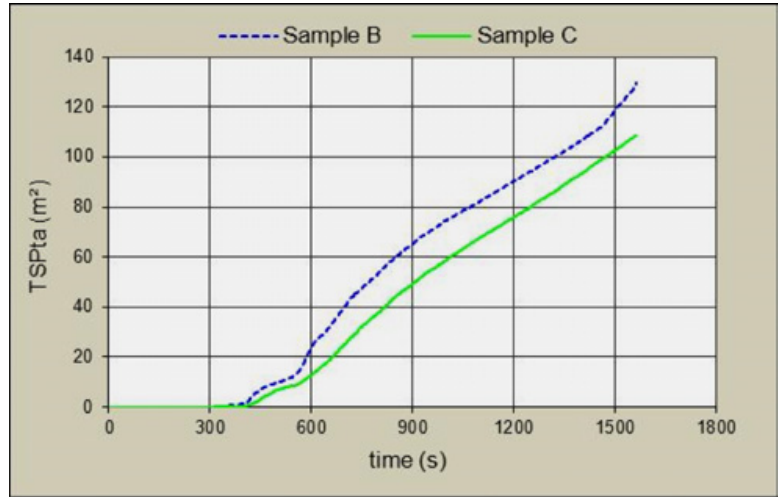

Figure 11. TSP of samples B and C in comparison.
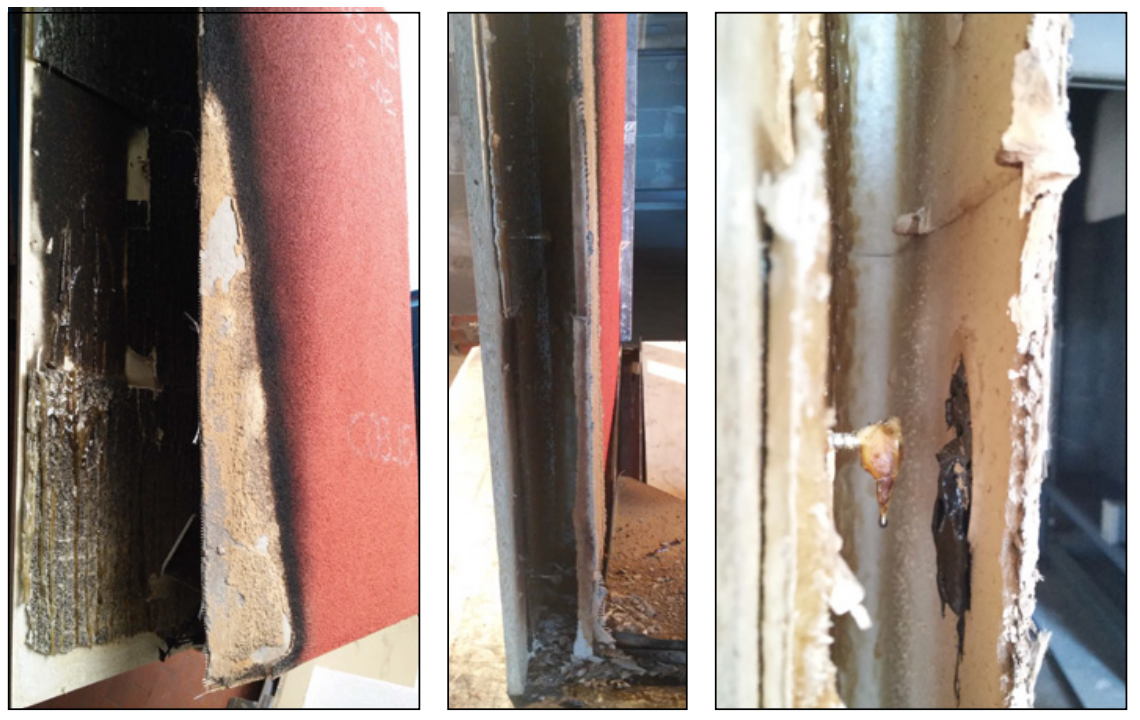

Figure 12. Samples B and $\mathrm{C}$ after removing short wings: gaps resulting after insulation melting.

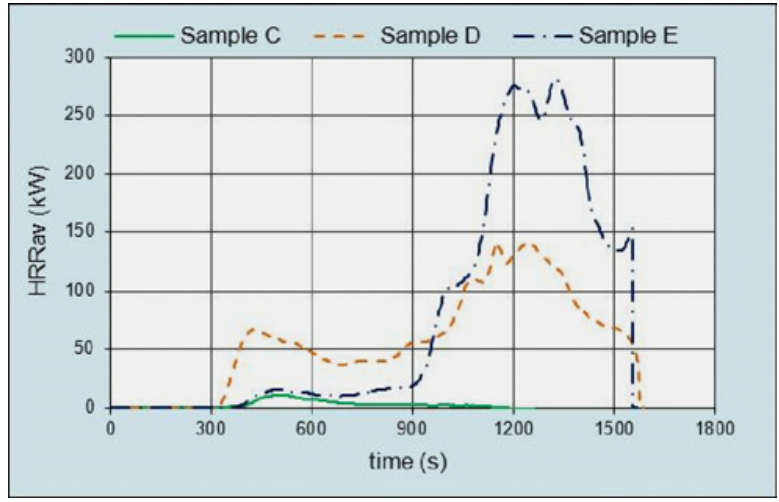

Figure 13. $\mathrm{HRR}_{\mathrm{av}}$ of samples $\mathrm{D}, \mathrm{C}$ and $\mathrm{E}$. 


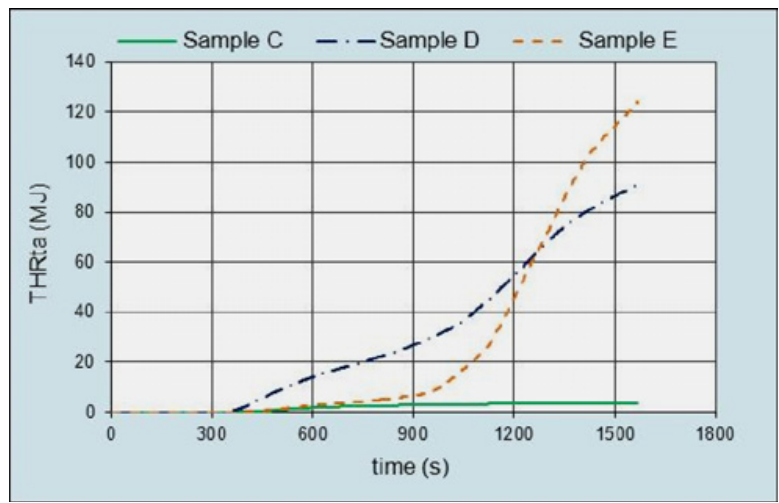

Figure 14. THR of samples D, C and E.

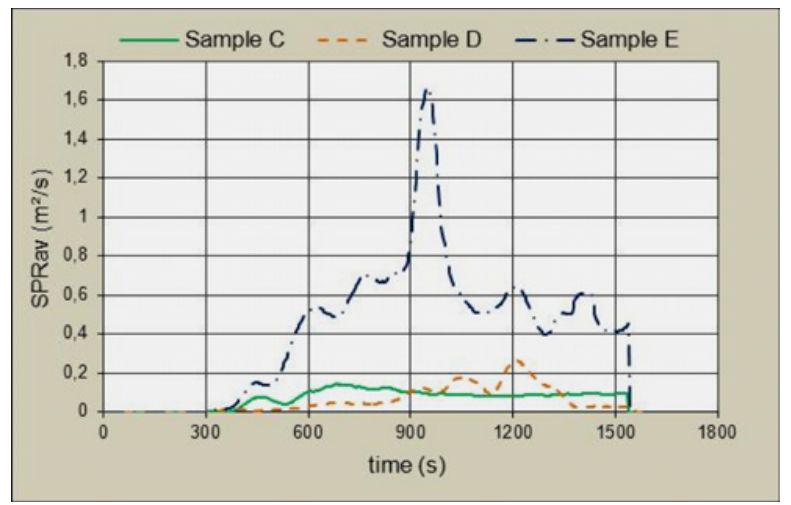

Figure 15. $\mathrm{SPR}_{\mathrm{av}}$ of samples $\mathrm{D}, \mathrm{C}$ and $\mathrm{E}$.

Table 4. Main data from SBI tests of samples D, C and E.

\begin{tabular}{|c|cc|c|c|}
\hline Sample & Peak HRRav $(\mathrm{kW})$ & $\mathrm{t}_{\mathrm{t}}(\mathrm{s})$ & $\mathrm{THR}_{\mathrm{ta}}(\mathrm{MJ})$ & Figra $(\mathrm{W} / \mathrm{s})$ \\
\hline $\mathrm{D}$ & 141.7 & 849 & 26.8 & 598.93 \\
\hline $\mathrm{C}$ & 10.6 & 225 & 2.9 & 58.92 \\
\hline E & 281.1 & 1026 & 6.6 & 306.24 \\
\hline
\end{tabular}

(at the end of the tests it has been noted that the amplitude of the affected part to liquefaction remains almost identical with changes only in the thickness).

\section{RESULTS: EFFECTS OF ACCIDENTAL DAMAGE}

The following results have been processed from tests of samples " $D$ ", "C" and "E" and aimed to point out the effects on fire behaviour of the same ETICS (insulation thickness $=40 \mathrm{~mm}$ ) with or without an artificial damage on the surface when assembled on wood particle boards (fire reaction class D-s1, d0).

\subsection{Considerations}

The presence of a little damage in the rendering layer totally changes the fire behavior of the insulation system. After an initial phase $\left(t-t_{0} 300 \mathrm{~s}\right)$ in which the samples behave essentially in the same way 
$2^{\text {nd }}$ International Seminar for Fire Safety of Facades, Lund (Sweden), 2016

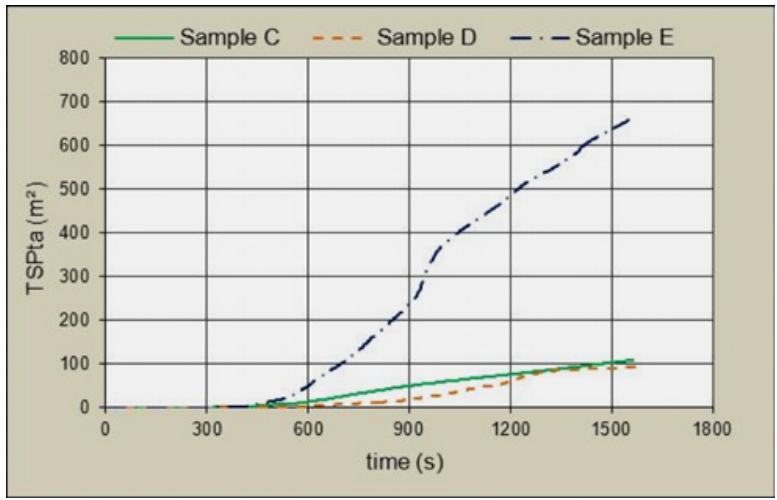

Figure 16. TSP of samples D, C and E.
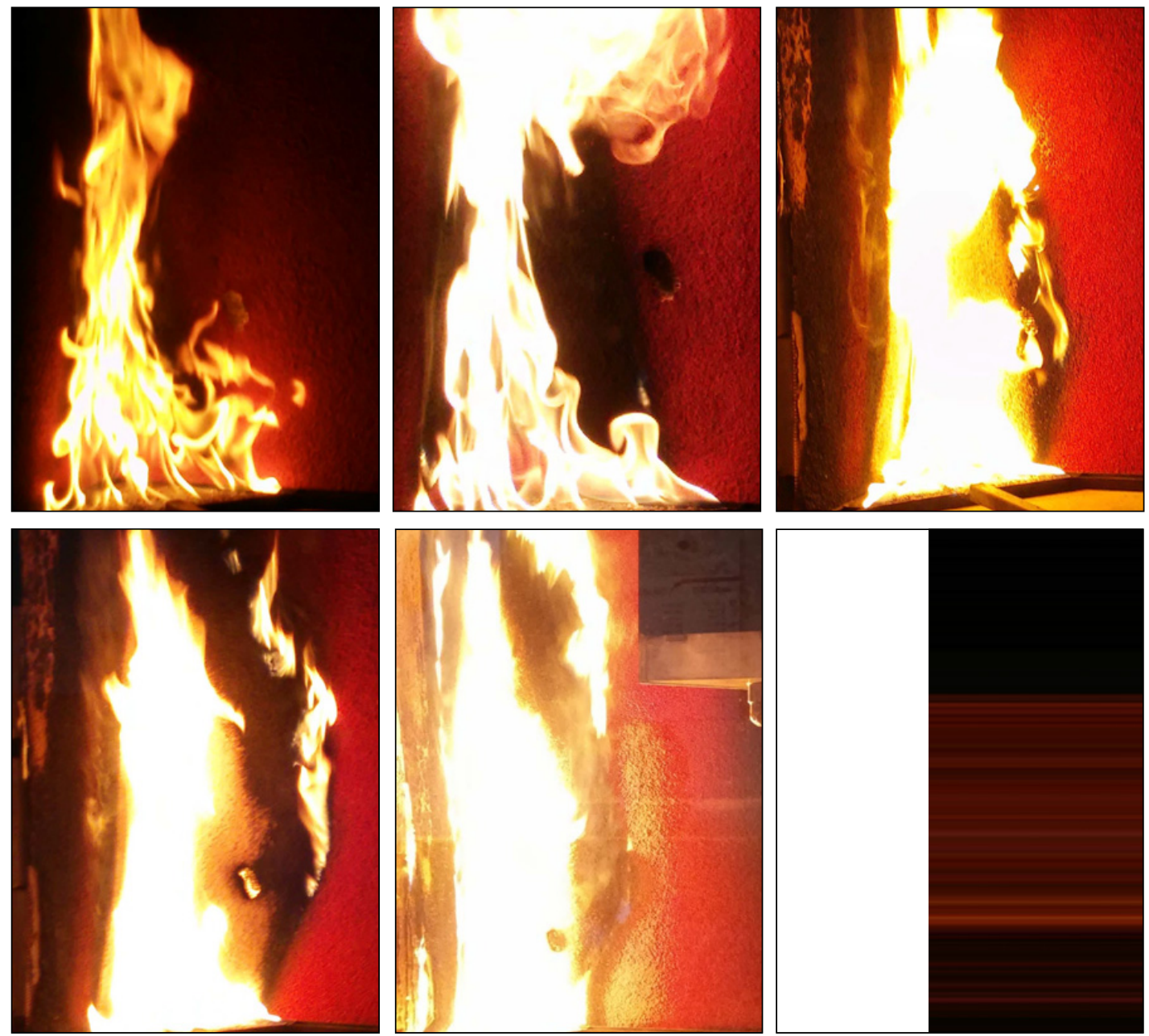

Figure 17. Sample E: pictures of flame propagation, due to the presence of damage, taken at different time steps of the test $\left(\mathrm{t}-\mathrm{t}_{0} 15,120,261,378,690\right.$, and $1263 \mathrm{~s}$. 


\section{MATEC Web of Conferences}



Figure 18. $\mathrm{HRR}_{\mathrm{av}}$ of samples $\mathrm{D}, \mathrm{F}$ and $\mathrm{G}$.

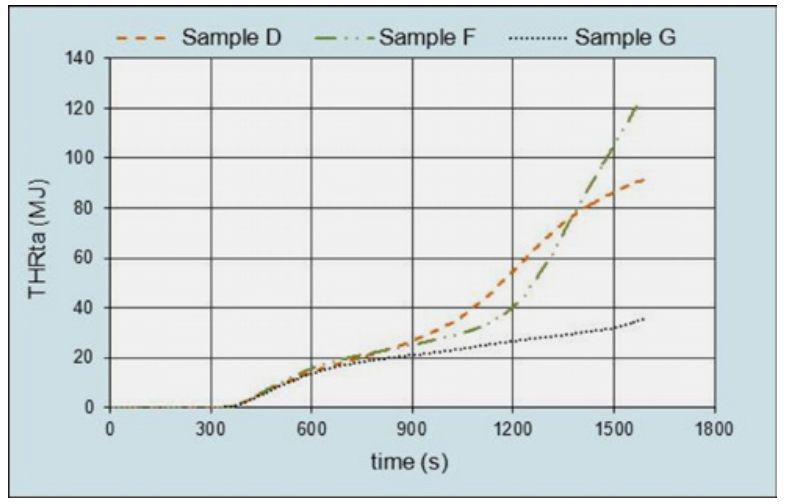

Figure 19. THR of samples D, F and G.

(only contribution to the organic part of the coating surface struck directly by the flame of the burner) due to heating of the surface and to the flame propagation, it liquefies the insulating material up to the "damage". The flame enters and exits from the surface through the artificial cavity and directly attacks the insulating material, in areas which would otherwise not affected, liquefying. Most ventilation in the gap that has developed between rendering and substrate feeds the flame. It is also interested the substrate of wood particles. It has a sudden increase of HRR (and of smoke) which it is greater even than that obtained in the case of sample D (wood particle boards only) in view of the presence of most combustible material (EPS). The comparison between sample E and D in the initial stage, shows once again how the rendering layer although damaged, performs protective function of the insulation and, more so, of the substrate, leading to recorded values for the heat and smoke very different from each other.

\section{RESULTS: INSIDE FIRE ATTACK $(i \rightarrow 0)$}

The following results have been processed from tests of samples " $F$ " and "G" in comparison with " $D$ " and aimed to point out the different fire behaviour of ETICS, with different thickness of the insulation layer (40 and $200 \mathrm{~mm}$ ) but reversed assembled on wood particle boards (fire reaction class D-s1, d0) to be subjected at the fire attack from inside. 


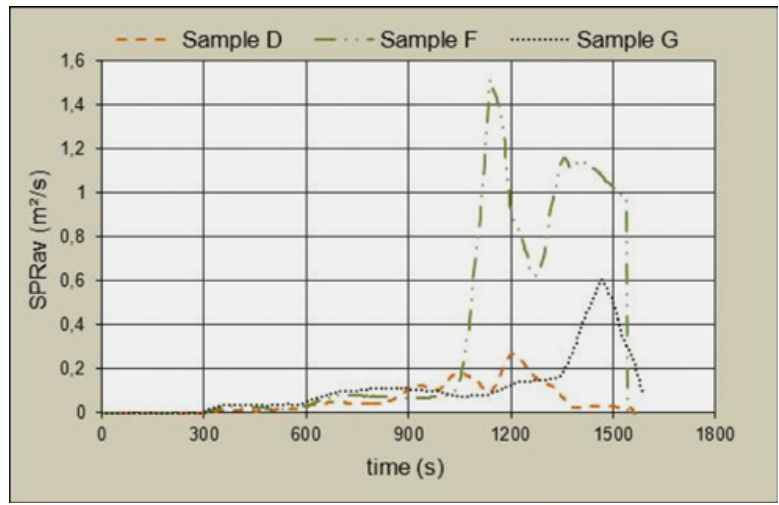

Figure 20. $\mathrm{SPR}_{\mathrm{av}}$ of samples $\mathrm{D}, \mathrm{F}$ and $\mathrm{G}$.

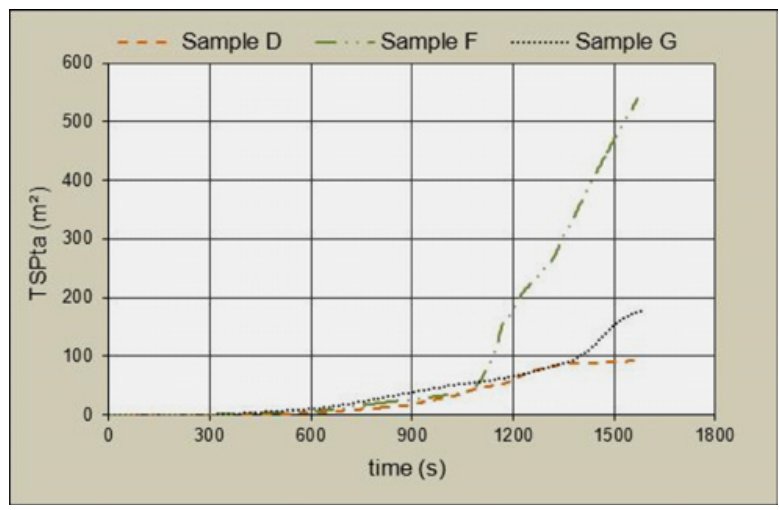

Figure 21. TSP of samples D, F and G.

Table 5. Main data from SBI tests of samples D, F and G.

\begin{tabular}{|c|cc|c|c|}
\hline Sample & Peak HRRav $(\mathrm{kW})$ & $\mathrm{t}-\mathrm{t}_{0}(\mathrm{~s})$ & $\mathrm{THR}_{\mathrm{ta}}(\mathrm{MJ})$ & Figra $(\mathrm{W} / \mathrm{s})$ \\
\hline $\mathrm{D}$ & 141.7 & 849 & 26.8 & 598.93 \\
\hline $\mathrm{F}$ & 262.0 & 1044 & 25.2 & 635.13 \\
\hline $\mathrm{G}$ & 63.8 & 156 & 21.0 & 544.92 \\
\hline
\end{tabular}

\subsection{Considerations}

These tests have been done to check how it can be modified the reaction to fire of a wall of wood-based that is externally coated with an insulation system (ETICS). The analysis of the data shows that in a first initial phase ( $\left(-t_{0} 400 \mathrm{~s}\right)$ the behaviour is substantially equal, being interested only the same material (wood particle board) in the combustion. Following the results deviate between them, in particular the one with insulation layer of $40 \mathrm{~mm}$ behaves in a completely analogous way to that of the same thickness with damage and attacked by the part of the rendering layer (sample E) that we have seen previously. When the combustion of the wood based board allows to directly attack the insulation layer, is retracts exposing the rendering layer. The relatively short distance between the flame (wood board is burning) and rendering layer and insulation system allows the latter to invest directly: It begins the combustion of its organic part. The opening of even small passages in the rendering layer increases oxygenation and leads to the almost complete combustion of the sample. 


\section{MATEC Web of Conferences}
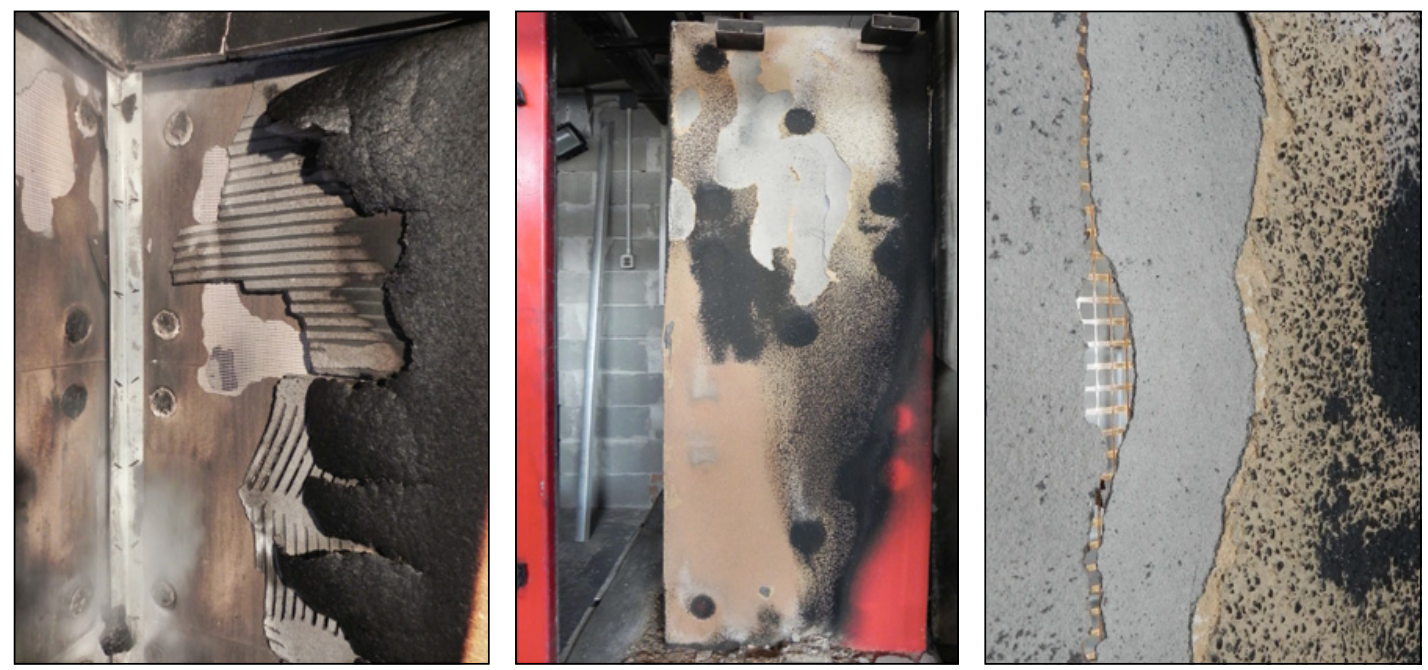

Figure 22. Sample F with thickness $40 \mathrm{~mm}$ at the end of test: inside and outside view.
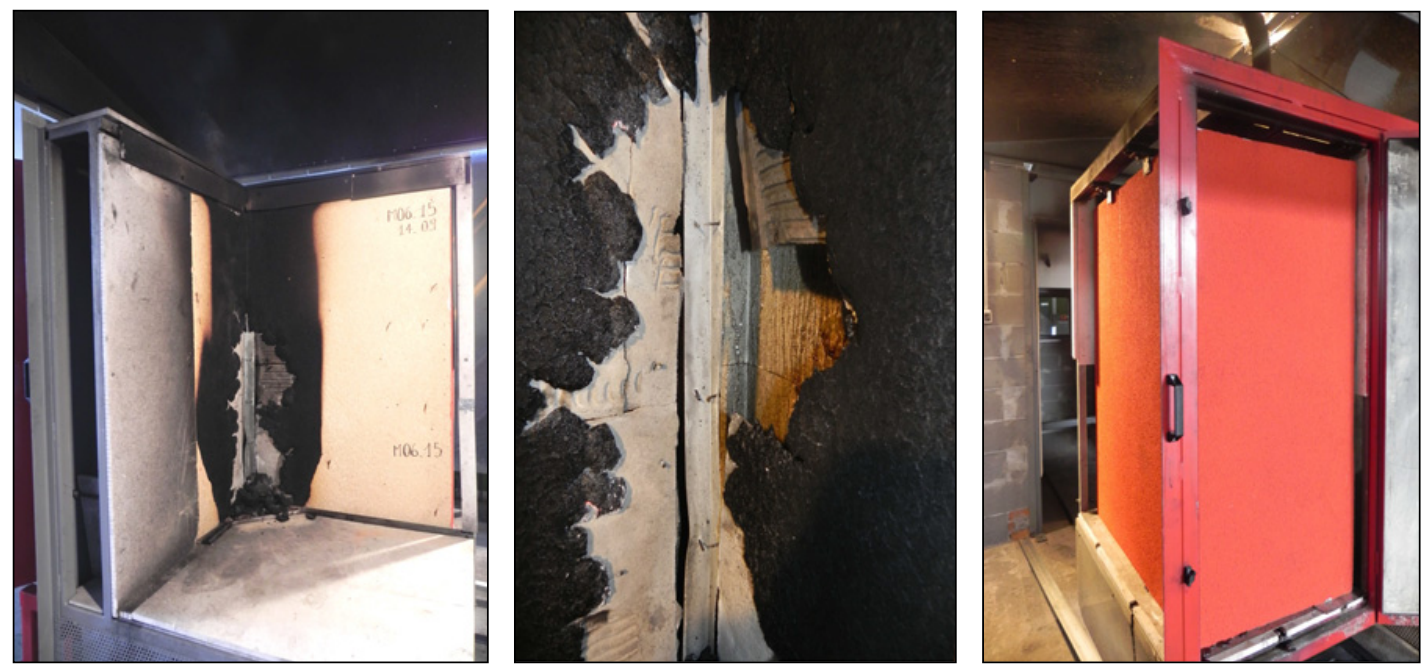

Figure 23. Sample $\mathrm{G}$ with thickness $200 \mathrm{~mm}$ at the end of test. inside and outside view.

The situation is different for the sample with insulation layer of $200 \mathrm{~mm}$ : the most amount of insulation material, and the distance between the wood board and rendering layer, do not allow the complete combustion of the sample. The wood board remains somewhat "protected" by the Non-Melting of insulation material which is not allowing in this way the oxygenation and cause suffocation of the flame.

\section{CONCLUSIONS}

It is well known that it is necessary to resort to large-scale fire testing to determine the fire performance of external cladding system; despite this and the outdated determination of the European Commission to develop a harmonized test (harmonized test specification) we are still far from the final result. While 
the EOTA Technical Report N.073 [7] is still under discussion, the market does not stop and the use of high-performance systems, from the point of view of energy saving as the ETICS, continues to be employed and encouraged from member states to achieve objectives set by international environmental protocols. Consequently, the study presented is based on the results obtained on samples that have been tested with a shared test method (EN 13823 SBI) while knowing the limits, acting rather on the definition of mounting (samples reversed) and sample preparation in order to highlight the performance obtainable in specific end uses and this, could also resort to the use of the European fire classification system without any alteration. A first result highlighted by the work here presented is, how the different type of substrate, to which is applied the insulation system considered does not necessarily imply a change in performance in terms of reaction to fire as well as the increase of thickness of insulating material fuel (EPS). It emerges clearly from the results of tests performed on samples with artificial damage as the true discriminating role is played by the rendering layer, or by its nature, integrity, ability to perform a protective function. Hence the need to study the possible consequences, not only in the case of evident accidental damage, such as that reproduced, but also when caused by incorrect assembly (wrong overlaps of the mesh, thin thickness of the coating layers, etc.) or due to aging phenomena (i.e. cracks formation as a result of hygrothermal cycles). Without such data are not surprising the specific decisions, in some Member States, to regulate the reaction to fire class of insulation products, or alternatively (such as in Italian [8] or Danish state [9]) to require the addition of protective coating systems, separately defined about the specific reaction to fire, and so distorting the concept of system, as a whole, of the product ETICS.

\section{References}

[1] EN 13501-1:2007+A1:2009 Fire classification of construction products and building elements. Classification using test data from reaction to fire tests.

[2] EN 13823:2010+A1:2014 Reaction to fire tests for building products. Building products excluding floorings exposed to the thermal attack by a single burning item.

[3] EN 13238:2010 Reaction to fire tests for building products. Conditioning procedures and general rules for selection of substrates.

[4] EOTA GUIDELINE FOR EUROPEAN TECHNICAL APPROVAL of External Thermal Insulation Composite Systems (ETICS) with Rendering - Edition 2000 Amended February 2013.

[5] Drysdale, D., An Introduction to Fire Dynamics, John Wiley \& Sons, 1992.

[6] Antonatus, E "Fire safety of Etics with EPS material properties and relevance for fire safety during transport, construction and under end use conditions in external thermal insulation component system”, Proceedings of 1st International Seminar for Fire Safety of Façade, Matec 9, 01001, 2013

[7] Technical Report N073 "Large Scale Fire Performance Testing of External Wall Cladding Systems”, EOTA PT4 Task group, 2013.

[8] ITALIAN FIRE CODE, "Guida Tecnica Requisiti di Sicurezza Antincendio delle Facciate negli Edifici Civili”, Ministero dell'interno, circolare n. 5043, 2013.

[9] Dragsted, A. and Vestergaard, A. B., "A new approach to the Danish guidelines for fire protection of combustible insulation". Proceedings of 1st International Seminar for Fire Safety of Façade, Matec 9, 01001, 2013. 